\title{
LQR/Sliding Mode Controller Design Using Particle Swarm Optimization for Crane System
}

\author{
Hazem I. Ali ${ }^{1}$, Azhar J. Abdulridha ${ }^{2 *}$, Rawaa R. Khaleel ${ }^{3}$, Kareem A. Hussein ${ }^{4}$
}

\section{Authors affiliations: \\ 1) Control and Systems \\ Engineering Dept., \\ University of Technology \\ Baghdad-Iraq. \\ 60143@,uotechnology.edu.iq \\ 2*) Control and Systems \\ Engineering Dept., \\ University of Technology \\ Baghdad-Iraq. \\ 60147@,uotechnology.edu.iq}

3) Control and Systems

Engineering Dept.,

University of Technology

Baghdad-Iraq.

rawaa521@yahoo.com

4) Control and Systems

Engineering Dept.,

University of Technology

Baghdad-Iraq.

Kareem control1994@yahoo.com

\section{Paper History:}

Received: 29 $9^{\text {th }}$ Oct. 2019

Revised: $8^{\text {st }}$ Jan. 2020

Accepted: 29th Jan. 2020

\begin{abstract}
In this work, the design procedure of a hybrid robust controller for crane system is presented. The proposed hybrid controller combines the linear quadratic regulator (LQR) properties with the sliding mode control (SMC) to obtain an optimal and robust LQR/SMC controller. The crane system which is represented by pendulum and cart is used to verify the effectiveness of the proposed controller. The crane system is considered one of the highly nonlinear and uncertain systems in addition to the under-actuating properties. The parameters of the proposed LQR/SMC are selected using Particle Swarm Optimization (PSO) method. The results show that the proposed LQR/SMC controller can achieve a better performance if only SMC controller is used. The robustness of the proposed controller is examined by considering a $\pm 50 \%$ variation in system parameters with applying an external disturbance input. Finally, the superiority of the proposed $\mathrm{LQR} / \mathrm{SMC}$ controller over the SMC controller is shown in this work.

Keywords: Linear Quadratic Regulator (LQR), Sliding Mode Control (SMC), PSO, LQR/Sliding Mode Controller, Full State Feedback.

$$
\text { تصميم مسيطرالمنظم التريبي الحطبي ذي النمط الإنزلاقي باستخدام أمثلية سرب الجنام }
$$$$
\text { حازم ابراهيم علي ، ازهار جبار عبدالرضا، رواء رفعت خليل ، كزيم علي حسين }
$$

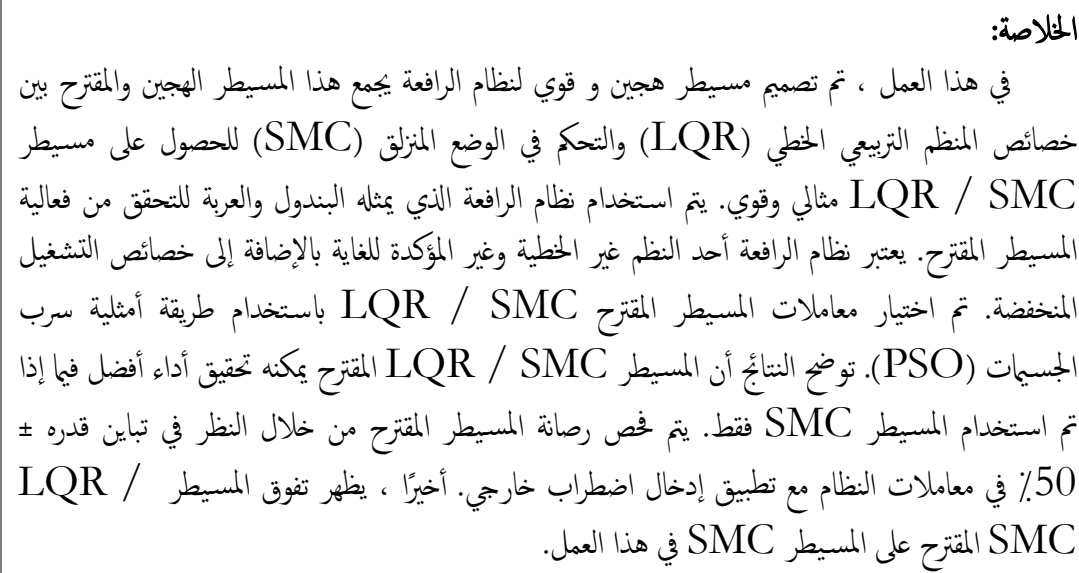

for the heavy loads transfer. The undesirable load swing causes by the crane acceleration and having negative consequences and safety performances on the system control. For the load position, a minimizing of load swinging is necessary for controlling on load swing angle. The derivations of swing angle and the cart position should be controlled. It is impossible to completely isolate the controlled object from undesired influences which are usually represented as external disturbances which minimized by the controller action [3]. 
On the other hand, the Linear Quadratic Regulator (LQR) is one of the optimal control methods and it is the most widely used in aerospace systems. This controller can achieve a desirable performance with control effort. However, the LQR controller cannot give the same performance in case of disturbance or in case of system parameters change $[4,5]$. The Sliding Mode Control (SMC) is robust technique which can be implemented by changing the structure of controller. In the SMC, state of the system trajectory is forced to move along a selected sliding surface. The sliding surface is always selected in such a way that made the system is stable depending on control law [6]. The SMC is low sensitivity to variations in system parameters and external disturbances [7].

There are several control schemes have been developed to improve the crane operation performance such as input shaping control, optimal control and fuzzy control [2]. Chang [8], proposed an adaptive fuzzy control to achieve precise position control and fast damping of load swing in spite of the load mass, flexible length of wire, and external disturbance of the crane. Hua et al [9], presented an adaptive nonlinear coupling control law based on Lyapunov stability for the motion control of the crane. The results showed better performance in comparison to the conventional PD control and sliding mode controller. Park et al [10], used an adaptive fuzzy sliding mode control to achieve a better performance for the robust anti-sway trajectory tracking of the crane for both uncertainty and nonlinearity. Bruin [1], made a comparison among four control methods which are a parallel Pcontroller, cascade P-controller, fuzzy controller and an internal model controller. The controllers except the internal model controller have achieved the stabilization and tracking of the system to a desired position. Burul et al. [3] made a comparison between $\mathrm{H}_{\infty}$ controller and pole placement control. $\mathrm{H}_{\infty}$ controller has ensured a system response with minimum steady state error, while the pole placement method failed to achieve that. Fang et al. [11], achieved a superior performance using a $S$-shape trajectory for the trolley and an adaptive controller to reduce payload swing. The adaptive control has achieved an asymptotic tracking even in the presence of variations in system parameters and external disturbances. Jaafar et al [12], designed the optimal controller gains for PID and PD controllers by improved PSO algorithm using a priority-based fitness method. The gains was examined based on a control structure that utilized for position and oscillation control of the system. Ismail et al [2], designed a robust SMC for a crane system with disturbances and uncertain parameters. Wang et al [13], proposed a dynamic sliding mode variable structure control for controlling the anti-swing position of overhead traveling crane with external disturbance and parameters uncertainty.

In this work, the LQR/SMC controller is proposed to stabilize the crane system and achieve a desirable tracking. The PSO method is used to optimize the controller parameters subject to a proposed cost function.

\section{System Mathematical Model}

The crane system can be represented as pendulum and cart. The mechanical model of the pendulum is presented as nonlinear system in Fig. 1 [14]:

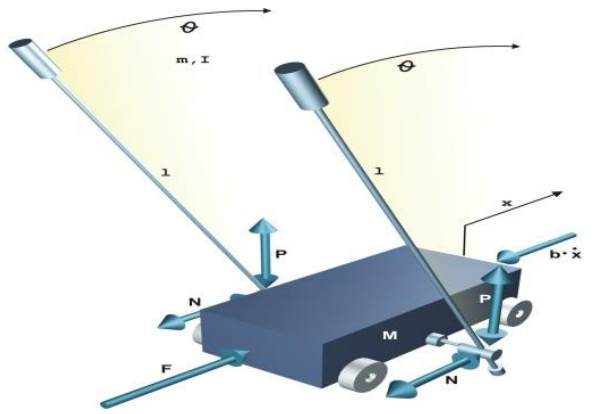

Figure (1): The mechanical model of the pendulum [14].

The summing of the forces and the moments acting on the pendulum and cart system can be expressed by the following nonlinear equations of motion $[8,14]$ :

$(m+M) \ddot{x}+b \dot{x}+m l \ddot{\theta} \cos \theta-m l \dot{\theta}^{2} \sin \theta=F \quad \ldots(1)$ $\left(I+m l^{2}\right) \ddot{\theta}-m g l \sin \theta+m l \ddot{x} \cos \theta+d \dot{\theta}=0 \ldots(2)$

where $m$ is the pole mass, $M$ is the cart mass, $b$ is the cart friction coefficient, $l$ is the pole length, $I$ is the moment of inertia of the pole, $g$ is the earth gravity, $d$ is the pendulum damping coefficient, $x$ is the cart position, $\dot{x}$ is the cart velocity, $\dot{x}$ is the cart acceleration, $\theta$ is the pendulum angular position, $\dot{\theta}$ is the pendulum angular velocity, $\ddot{\theta}$ is the pendulum angular acceleration and $F$ is the force applied on the crane system. The motion eq. 1 and eq. 2 can be linearized to be $[8,14]$ :

$$
\begin{gathered}
(m+M) \ddot{x}+b \dot{x}-m l \ddot{\theta}=F \\
\left(I+m l^{2}\right) \ddot{\theta}+m g l \theta-m l \ddot{x}+d \dot{\theta}=0
\end{gathered}
$$

To find $\ddot{x}$ and $\ddot{\theta}$, equations eq. 3 and eq. 4 are simplified to give:

$$
\begin{aligned}
& \ddot{x}=\frac{\left(I+m l^{2}\right)(F-b \dot{x})-(m l g \theta+d \dot{\theta})(m l)}{(m+M)\left(I+m l^{2}\right)-(m l)^{2}} \\
& \ddot{\theta}=\frac{(-m l g \theta-d \dot{\theta})(m+M)+(m l)(F-b \dot{x})}{(m+M)\left(I+m l^{2}\right)-(m l)^{2}}
\end{aligned}
$$

Assuming $\quad x_{1}=x, x_{2}=\theta, x_{3}=\dot{x}, x_{4}=\dot{\theta} \quad$ and $u=F$, the state equations of crane system are:

$$
\begin{gathered}
\dot{x}_{1}=x_{3} \\
\dot{x}_{2}=x_{4} \\
\dot{x}_{3}=\frac{\left(7+m l^{2}\right)\left(u-b x_{3}\right)-\left(m l g x_{2}+d x_{4}\right)(m l)}{(m+M)\left(I+m l^{2}\right)-(m l)^{2}} \\
\dot{x}_{4}=\frac{\left(-m l g x_{2}-d x_{4}\right)(m+M)+(m l)\left(u-b x_{3}\right)}{(m+M)\left(I+m l^{2}\right)-(m l)^{2}}(10)
\end{gathered}
$$

The state space representation for linear model is:

$$
\dot{x}=A x(t)+B u(t)
$$

where $x \in R^{n}, u \in R^{n}, n=4, x=[x, \theta, \dot{x}, \dot{\theta}]^{T}=$ $\left[x_{1}, x_{2}, x_{3}, x_{4}\right]^{T}$ and the initial condition is: $x_{0}=$ $\left[\begin{array}{llll}0.1 & 190^{\circ} & 0 & 0\end{array}\right]^{T}$. The state space representation of Crane system will be: 


$$
\begin{aligned}
& {\left[\begin{array}{l}
\dot{x_{1}} \\
\dot{x_{2}} \\
\dot{x_{3}} \\
\dot{x_{4}}
\end{array}\right]=\left[\begin{array}{cccc}
0 & 0 & 1 & 0 \\
0 & 0 & 0 & 1 \\
0 & \frac{-g g_{2}{ }^{2}}{g_{1} g_{3}-g_{2}^{2}} & \frac{-b g_{3}}{g_{1} g_{3}-g_{2}{ }^{2}} & \frac{-d g_{2}}{g_{1} g_{3}-g_{2}{ }^{2}} \\
0 & \frac{-g g_{1} g_{2}^{2}}{g_{1} g_{3}-g_{2}^{2}} & \frac{-b g_{2}}{g_{1} g_{3}-g_{2}{ }^{2}} & \frac{-d g_{1}}{g_{1} g_{3}-g_{2}{ }^{2}}
\end{array}\right]\left[\begin{array}{l}
x_{1} \\
x_{2} \\
x_{3} \\
x_{4}
\end{array}\right]+} \\
& {\left[\begin{array}{c}
0 \\
0 \\
\frac{g_{3}}{g_{1} g_{3}-g_{2}^{2}} \\
\frac{g_{2}}{g_{1} g_{3}-g_{2}^{2}}
\end{array}\right] \mathrm{u} } \\
& \text { where } g_{1}=(m+M), g_{2}=(m l) \text { and } g_{3}=(I+
\end{aligned}
$$
$\left.m l^{2}\right)$. Table 1 lists the Crane model parameters.

Table (1): Crane model parameters [14].

\begin{tabular}{|c|c|}
\hline Parameter & Value/ Unit \\
\hline$g$ & $9.81 \mathrm{~m} / \mathrm{sec}^{2}$ \\
\hline$l$ & 0.36 to $0.4 \mathrm{~m}$ \\
\hline$M$ & $2.4 \mathrm{~kg}$ \\
\hline$m$ & $0.23 \mathrm{~kg}$ \\
\hline$I$ & $0.099 \mathrm{~kg} \cdot \mathrm{m}^{2}$ \\
\hline$b$ & $0.05 \mathrm{~N} . \mathrm{sec} / \mathrm{m}$ \\
\hline$d$ & $0.005 \mathrm{~N} . \mathrm{msec} / \mathrm{rad}$ \\
\hline
\end{tabular}

In a real time, the cart position and the control signal are bounded when designing the controller. The range of the control signal should be around [$2.5 \mathrm{~V},+2.5 \mathrm{~V}]$ and the magnitude of generated force is $[-20.0 N,+20.0 N]$. By the rail length of the cart position which is bounded as $[-0.5 m,+0.5 m][14,15]$.

\section{Controller Design}

The SMC includes two phases which are the reaching phase and the sliding phase. In the reaching phase, a reaching control law is applied to drive states of the system to the sliding surface rapidly. In the sliding phase, when the system states are on the sliding surface, an equivalent control law is applied to force the state of system along the sliding surface to the origin. Fig. 2 illustrates the reaching phase and the sliding phase in the SMC design $[6,16,17]$.

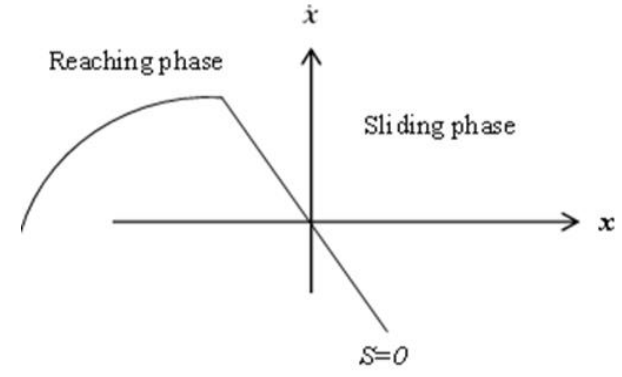

Figure (2): Two phase of SMC.

There are two steps to design SMC controller which consists of find the sliding surface and then design the control input to force the system states toward the sliding surface [6]. For the Crane system which has one input there is one sliding mode surface which can be defined as:

$$
S(t)=G x(t)
$$

where $G$ is $m \times n$ matrix which represents the gain to inform sliding surface. Differentiating eq.13 and substituting Eq.11 in the resulting equation, yields [6]:

$$
\dot{S}(t)=G(A x(t)+B u(t))
$$

The sliding mode control law is:

$$
u(t)=u_{e q}(t)+u_{s}(t)
$$

where $u_{e q}(t)$ is an equivalent control input and $u_{s}(t)$ is discontinuous control input. The vector $S(t)=0$ represents the intersection of the sliding surface passing through the origin. The equivalent control input $u_{e q}(t)$, corresponds to $\dot{S}(t)=0$. Therefore, from eq.14 [6], the equivalent control input $u_{e q}(t)$ will be:

$$
u_{e q}=-(G B)^{-1} G A x
$$

the matrix $G B$ must be nonsingular. The reaching condition for the surface is $S \dot{S}<0$ so that

$$
\dot{S}=g_{0} \operatorname{sgn}(\mathrm{S})
$$

where $g_{0}$ is a positive scalar gain.

The discontinuous control input $u_{s}$ has the following form:

$$
u_{s}=-(G B)^{-1} g_{0} \operatorname{sgn}(\mathrm{S})
$$

Substituting eq.16 and eq.18 in eq.15, the control law becomes:

$$
u=-(G B)^{-1}\left\{G A x+g_{0} \operatorname{sgn}(\mathrm{S})\right\}
$$

The $G$ matrix is selected by trial and error as $\left[\begin{array}{llll}0.5 & 0.5 & 0.5 & -0.1\end{array}\right]$ and $g_{0}=10$ for crane system.

During sliding mode control implementation a chattering phenomenon is appeared. The chattering phenomenon happened because of unmolded dynamics of system and discretization chattering. To attenuate the undesired effects of the chattering phenomenon, Slotine [16] proposed an adoption of a thin boundary layer neighboring the switching surface, the Sign function replacing by a Hyperbolic Tangent function $(\tanh (S))$, and the control law becomes:

$$
u=-(G B)^{-1}\left\{G A x+g_{0} \tanh (S)\right\}
$$

To design an optimal SMC, the LQR will be added to the control law of the SMC. Consequently, the SMC law which is described in eq. 15 will be:

$$
u=\underbrace{-K x}_{\text {LR part }} \underbrace{-g_{0} \tanh (S)}_{S M C \text { part }}
$$

where $K$ is derived from minimization of the cost function represented by:

$$
J=\int_{0}^{\infty}\left(x^{T} Q x+u^{T} R u\right) d t
$$

where $Q$ and $R$ are positive semi-definite and positive definite Symmetric constant matrices, respectively. The weights $Q$ and $R$ can be time varying if needed. The pair $(A, B)$ must be controllable. Clearly, the controller cannot stabilize the system and perform as desired if the dynamics are not controllable. The LQR gain vector $K$ is [15]:

$$
K=R^{-1} B^{T} P
$$

where $P$ is a positive definite symmetric matrix and it obtained from the solution of the algebraic Riccati equation [5]:

$$
A^{-1} P+P A-P B R^{-1} B^{T} P+Q=0
$$


In this work, the weights $Q$ and $R$ are selected using PSO which is an efficient method for global optimization problems. Assuming particles are composed of a group in $n$ dimensional space, among them, the position and velocity of $i$ particle in the space are $x_{i}=\left(x_{i 1}, x_{i 2}, \ldots, x_{i D}\right), \quad v_{i}=$ $\left(v_{i 1}, v_{i 2}, \ldots, v_{i D}\right)$ where $i=1,2, \ldots, n$. The best position of the $i$ particle experiences is denoted by $p_{\text {best }}(i)$, and the best position of all the particles in the group experience is denoted by $g_{\text {best }}(i)$. The all particle swarm updates the position and velocity through tracking the individual extreme value and the optimal value. The particle optimization process is expressed in [18]:

$$
\begin{gathered}
x_{i d}^{k+1}=x_{i d}^{k}+v_{i d}^{k} \\
v_{i d}^{k+1}=w v_{i d}^{k}+c_{1} \alpha\left(p_{i d}^{k}-x_{i d}^{k}\right)+c_{2} \beta\left(p_{g d}^{k}-x_{i d}^{k}\right)
\end{gathered}
$$

where $w$ is the inertia weight; $c_{1}$ is the optimal value of the weight coefficient that the particle tracks its history; $c_{2}$ is the weight coefficients that particle track the optimal value; and $\alpha$ and $\beta$ are the random numbers changing in $[0,1] . p_{i d}^{k}$ is the individual optimal solution of the particle after the $k$ iterations; $p_{g d}^{k}$ is the global optimal solution of the group in the $k$ iterations [18, 19]. The linear quadratic performance index eq.22 is adopted as a fitness function. $Q$ and $R$ are symmetric positive definite matrix [20]. To simplify the problem, the parameters of $Q$ is selected as a diagonal matrix of $4 \times 4$ and $R$ is matrix of $1 \times 1$ as:

$$
Q=\operatorname{diag}[999.93,913.14,511.14,999.56],
$$

$$
R=0.94 \text {. }
$$

The resulting optimal feedback matrix is:

$$
K=\left[\begin{array}{llll}
28.037 & 61.22 & 32.31 & 1.57
\end{array}\right]
$$

The PSO method parameters after $k=10000$ iterations are set as $c_{1}=c_{2}=1.5$ and $w=2$. Fig.3 represents the block diagram for proposed LQR/SMC controller.

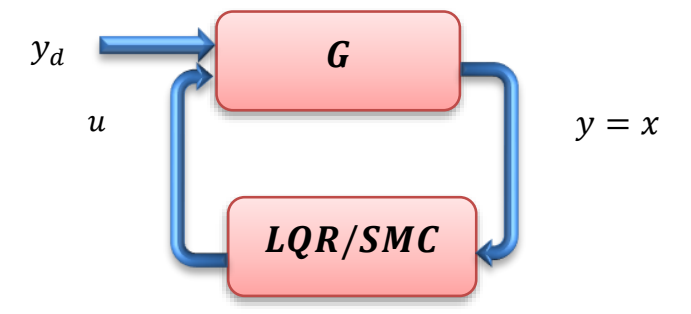

Figure (3): A full state feedback LQR/SMC controller.

\section{Results and Discussion}

Fig.4 shows the behavior of a Crane system before applying the proposed controller with zeros' initial condition. It is shown that the system cannot be tracking the desired position and it is out-off control and also the pendulum angle deviates with large values.

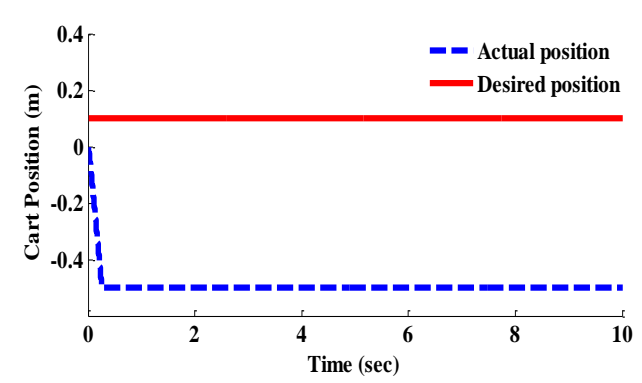

(a) cart position.

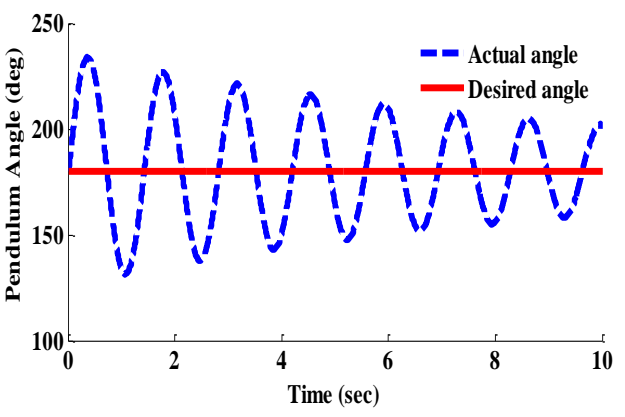

(b) pendulum angle.

Figure (4): Time response of a Crane System.

Fig. 5 represents of the nonlinear Crane system for SMC controller and LQR/SMC controller by the Simulink Matlab program.

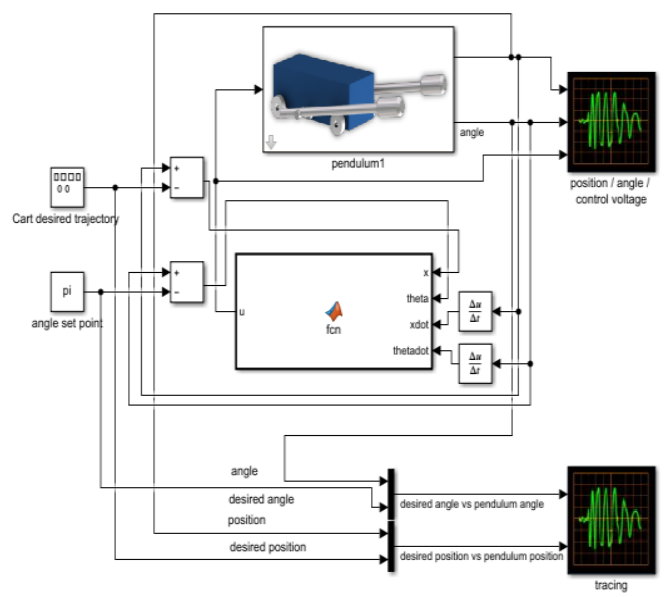

Figure (5): Simulink diagram of the nonlinear Crane system for SMC controller and LQR/SMC controller.

Fig.6 represents the time response of Crane system for cart position and pendulum angle using the proposed controller with initial conditions $\left\{0.1 \mathrm{~m}, 190^{\circ},(0,0) \mathrm{deg} / \mathrm{sec}\right\}$. The state trajectories using LQR/SMC controller approaches the equilibrium point faster than the state trajectories obtained using SMC controller.

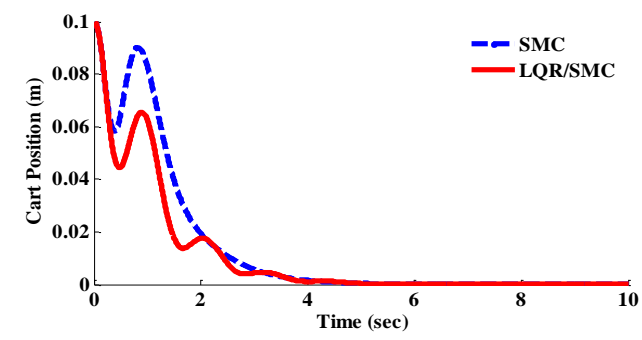

(a) cart position. 


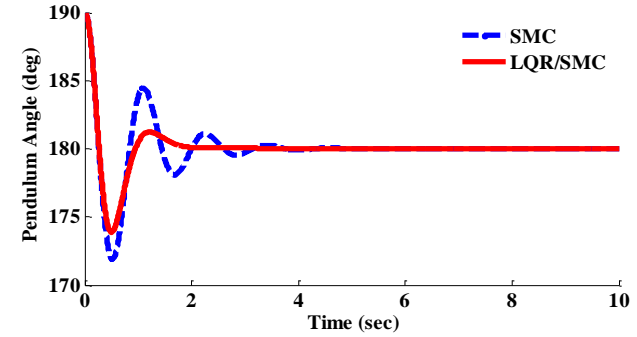

(b) pendulum angle.

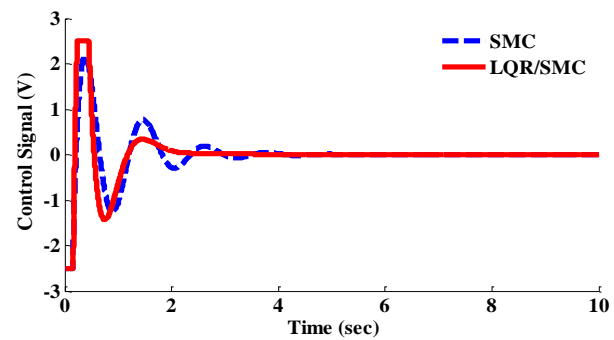

(c) control signal.

Figure (6): The states trajectories of the nonlinear Crane system for SMC controller and LQR/SMC

$$
\text { controller. }
$$

Fig. 7 represents the tracking properties of the system using the proposed LQR/SMC controller. It can be noticed from result that the proposed LQR/SMC controller can improve the system response significantly in case of pendulum angle. From this figure can noticed that, under effect SMC, the $t_{s}=5.12 \mathrm{sec}$ with $e_{s s}=0.01$ for cart position and $t_{s}=5.12 \mathrm{sec}$ with $e_{s s}=0.01^{\circ}$ for pendulum angle. In LQR $/ \mathrm{SMC}$ controller, the $t_{s}=4.02 \mathrm{sec}$ with $e_{s s}=0.01$ for cart position and $t_{s}=2.25 \mathrm{sec}$ with $e_{s S}=0.01^{\circ}$ for pendulum angle. So that, $\mathrm{LQR} / \mathrm{SMC}$ controller has given better performance and more smoothed than if only one of them is used. LQR/SMC controller has given best control action rather than SMC controller.

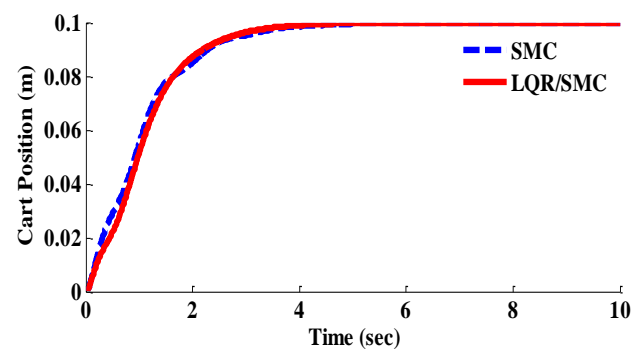

(a) cart position.

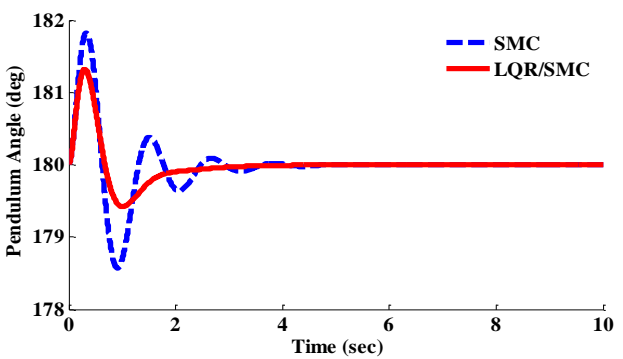

(b) pendulum angle.

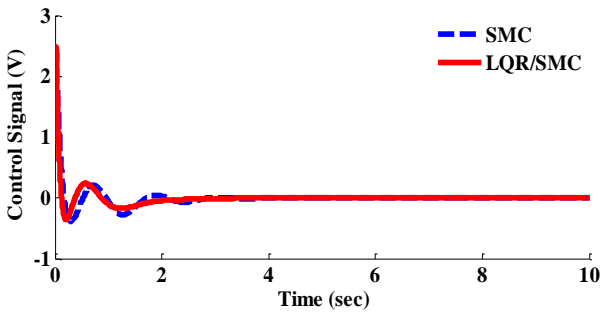

(c) control signal.

Figure (7): Tracking properties of the nonlinear Crane system using SMC controller and LQR/SMC controller.

To show the robustness of the proposed $\mathrm{LQR} / \mathrm{SMC}$ controller, an external disturbance is applied to the system at time $=4 \mathrm{sec}$ as shown in Fig.8. It can be notice that the proposed LQR/SMC controller can effectively reject the external disturbance and achieve the required robustness in comparison to SMC for the system.

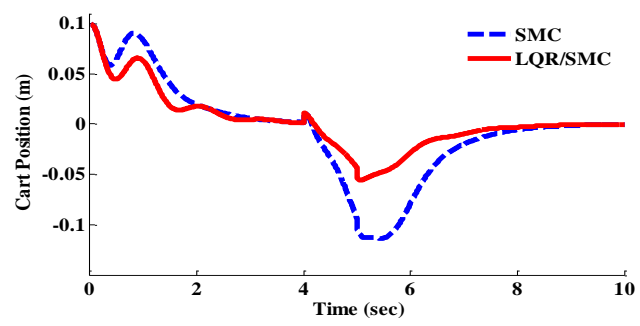

(a) cart position.

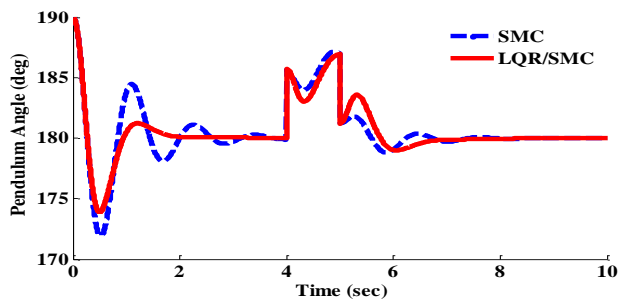

(b) pendulum angle.

Figure (8): Disturbance properties of the nonlinear Crane system using SMC controller and LQR/SMC controller.

Fig.9 shows the state trajectories of the system with LQR/SMC controller when a variation in parameters of the system about $\pm 50 \%$ is considered. It is apparent that the LQR/SMC controller can robustly compensate a variation in parameters and maintain the desired performance of the system.

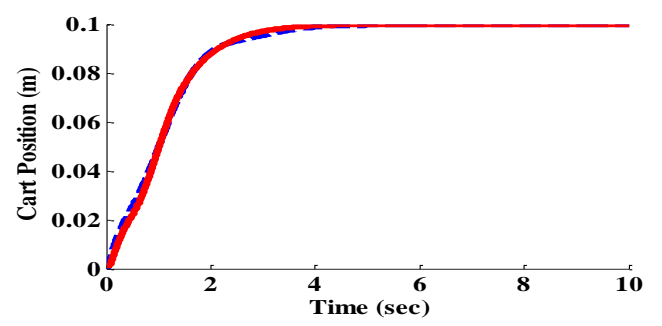

(a) cart position. 


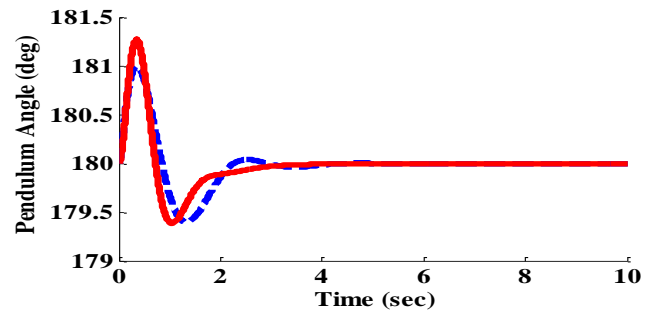

(b) pendulum angle.

Figure (9): Time response of the uncertain nonlinear Crane system with $\pm 50 \%$ perturbation in the system parameters using LQR/SMC controller.

\section{Conclusion:}

In this paper, the design of the hybrid LQR/SMC controller was presented. This controller combined the properties of LQR and SMC to obtain a new controller. This controller achieved a better performance than if SMC controller is used. The Crane system which is nonlinear and uncertain system was used to verify the effectiveness of the proposed LQR/SMC controller. The efficiency of the proposed LQR/SMC controller was examined with $\pm 50 \%$ variation in the system parameters and external disturbance. The results showed the superiority of the LQR/SMC controller over SMC controller.

\section{Reference:}

[1] Bruin S., "Comparison of Different Control Algorithms for a Gantry Crane System", Journal of Scientific Research, Intelligent Control and Automation, Vol.1,pp. 68-81, 2010.

[2] Ismail R., That N. D. and Ha Q. P., " Offshore Container Crane Systems with Robust Optimal Sliding Mode Control" Conference Proceeding, 31 International Symposium on Automation and Robotics in Construction and Mining, ISARC 2014 Proceedings, Sydney, Australia, pp.149 - 156, 2014.

[3] Burul I., Koloni F. and Matuško J., "The Control System Design of a Gantry Crane Based on Hळ Control Theory", Conference: MIPRO, 2010 Proceedings of the $33^{\text {rd }}$ International Convention, pp.183-188, 2010.

[4] Lavretsky E. and Wise K. A., "Robust and Adaptive Control with Aerospace Applications", Springer-Verlag, London, 2013.

[5] Prasad L. B., Tyagi B., Gupta H. O.," Optimal Control of Nonlinear Inverted Pendulum System Using PID Controller and LQR: Performance Analysis without and with Disturbance Input", International Journal of Automation and Computing, Vol. 11, No. 6, pp.661-670, 2014.

[6] Ali H. I. and Abdulridha A. J., "State Feedback Sliding Mode Controller Design for Human Swing Leg System", Al-Nahrain Journal for Engineering Sciences (NJES) Vol.21 No.1, pp.51-59, 2018.

[7] Agrachev A. A. , Morse A. S. , Sontag E. D., Sussmann H.J. and Utkin V. I., "Nonlinear and Optimal Control Theory", 2004, Cetraro, Italy.

[8] Chang C., "Adaptive Fuzzy Controller of the Overhead Cranes with Nonlinear Disturbance ", IEEE Transactions on Industrial Informatics, Vol. 3, No. 2, pp.164-172, 2007.
[9] Hua Y. J. and Shine Y. K.," Adaptive Coupling Control for Overhead Crane Systems", Journal ScienceDirect, Mechatronics, No.17, pp.143-152, 2007.

[10] Park M., Chwa D. and Hong S.," Antisway Tracking Control of Overhead Cranes with System Uncertainty and Actuator Nonlinearity Using an Adaptive Fuzzy Sliding-Mode Control", IEEE Transactions on Industrial Electronics, Vol. 55, No. 11, pp.3972- 3984, 2008.

[11] Fang Y., Ma B., Wang P. and Zhang X.," A Motion Planning-Based Adaptive Control Method for an Underactuated Crane System", IEEE Transactions on Control System Technology, Vol. 20, No. 1, pp.241- 248, 2012.

[12] Jaafar H. I., Mohamed Z., Zainal Abidin A. F. and Ab Ghani Z.," PSO-Tuned PID Controller for a Nonlinear Gantry Crane System", IEEE International Conference on Control System, Computing and Engineering, Penang, Malaysia, pp.23 $-25,2012$.

[13] Wang T., Tana N., Zhouc C., Zhanga C. and Zhid Y., "A Novel Anti-Swing Positioning Controller for Two Dimensional Bridge Crane via Dynamic Sliding Mode Variable Structure", $8^{\text {th }}$ International Congress of Information and Communication Technology (ICICT-2018), Procedia Computer Science, No.131, pp.626-632, 2018.

[14] Digital Pendulum Control Experiments Manual, Feedback Instrumentals Ltd, Uk, 2012.

[15] Das S., Pan I., Halder K., Das Sh. and Guptaa A., "Optimum Weight Selection Based LQR Formulation for the Design of Fractional Order $\mathrm{PI}^{\lambda} \mathrm{D}^{\mu}$ Controllers to Handle a Class of Fractional Order Systems", 2013 International Conference on Computer Communication and Informatics (ICCCI 2013), Coimbatore, India, 2013.

[16] Bessa W. M., "Some Remarks on the Boundedness and Convergence Properties of Smooth Sliding Mode Controllers", International Journal of Automation and Computing, Vol. 6, No. 2, pp.154158, 2009.

[17] Kapoor N. and Ohri J., "Integrating a Few Actions for Chattering Reduction and Error Convergence in Sliding Mode Controller in Robotic Manipulator", International Journal of Engineering Research and Technology (IJERT), Vol. 2 No.5, pp.2278-0181, 2013.

[18] Teja V. S., Shanavas T. N. and Patnaik S. K.," Modified PSO Based Sliding-Mode Controller Parameters for Buck Converter", IEEE Students' Conference on Electrical, Electronics and Computer Science, 2012.

[19] Guo X. and Liu X., "Particle Swarm Optimization Sliding Mode Control on Interconnected Power System", Proceedings of the $33^{\text {rd }}$ Chinese Control Conference, Nanjing, China, pp.93-97, 2014.

[20] Fang J., "The LQR Controller Design of TwoWheeled Self-Balancing Robot Based on the Particle Swarm Optimization Algorithm", Hindawi Publishing Corporation Mathematical Problems in Engineering, Vol. 2014, pp.1-7, 2014. 